\title{
MUSIC AND PERSONA: AN INTRODUCTION
}

\author{
Charles Fairchild and P. David Marshall
}

\begin{abstract}
Persona is a very mutable concept. Perhaps its mutability is no more prominently displayed that in its intersection and integration into music and musical culture. In this opening essay for our special issue on music and persona, we chart the meaning and the value of persona analyses to the study of music. Essentially, our objective here is two-fold. First, we want to provide a map of how persona has been employed in research in music. What this will generate is a critical investigation of these traditions, but also what we hope will be a valuable reference for future music and persona scholarship. Second, and of equal importance, is how these uses of musical persona can be further informed and assisted by the more recent scholarship in persona studies most openly articulated by this journal over the last five years, but also the widening array of related books, articles and book chapters that are percolating in connected fields. We attempt to pull together our review of the current field of music and persona with the urgent need to identify with greater thought and clarity the industrial structures that shape our relationship to music performance and its relation to audiences and its constitution of celebrated individuals and recognizable and market-sensitive personas. Our essay concludes with the introduction of our series of articles in this issue and how they intersect with these various traditions that have explored persona's imbrication into music.
\end{abstract}

\section{KEY WORDS}

Music; Persona; Musical Persona; Character; Identity; Popular Music; Celebrity

\section{INTRODUCTION}

Persona is a very mutable concept. Perhaps its mutability is no more prominently displayed than in its intersection and integration into music and musical culture. In this opening essay for our special issue on music and persona, we chart the meaning and the value of persona analyses to the study of music. Essentially, our objective here is two-fold. First, we want to provide a map of how persona has been employed in research in music. What this will generate is a critical investigation of these traditions, but also a valuable reference for future music and persona scholarship. ${ }^{i}$ And second, and of equal importance, is how these uses of musical persona can be further informed and assisted by the more recent scholarship in persona studies most openly articulated by this journal over the last five years, but also the widening array of related books, articles and book chapters that are percolating in connected fields. We attempt to pull together our review of the current field of music and persona with the urgent need to identify with greater thought and clarity the industrial structures that shape our relationship to music performance and its relation to audiences and its constitution of celebrated individuals and recognizable and market-sensitive personas. Our essay concludes with the introduction of our 
series of articles in this issue and how they intersect with these various traditions that have explored persona's imbrication into music.

\section{MUSIC's PERSONALITY SYSTEM(S)}

Because of persona's relationship to personality, it is understandable that there is a high expectation that musical persona is generally attributed to the visible figures who have performed and composed music. Indeed, the study of the most visible - what could be described as the celebrity structure of music and popular music - has been investigated effectively from a variety of perspectives. This tradition, with its clear emergence from original studies of stardom by scholars such as Richard Dyer, Edgar Morin (1972) and even Roland Barthes (1973; 1977), was somewhat skewed to film scholarship from the mid to late 20th century. Nonetheless, because of music's prominence in the performance of stardom by key film stars such as Judy Garland and Marilyn Monroe, in the work of Dyer (1998) it seamlessly translates across to performance and persona (Dyer 1998). Augmenting this, Marshall's work on popular music in Celebrity and Power, in which he linked popular music celebrity discourse in the 20th century to claims of authenticity and connection, particularly through an analysis of the boy band New Kids on the Block (Marshall 2014, pp. 150-184), defines a certain approach to popular music and public identity.

More recently - particularly in the study of popular music celebrity - there have been major efforts to decipher the meaning of key popular icons. This current research, which has had a focus on recent pop stars' post-death, includes a special issue on David Bowie (see Continuum special issue, Cinque and Redmond 2017) in particular. This trajectory of exploring the meaning and intent of a popular music icon identifies approaches that have emerged from the tradition of biography studies. The early investigations of Madonna paralleled the persona construction and chameleon-like behaviour and performance of Bowie and led to studies of her play with identity (see for example, Guilbert 2002). In the past 10 years, these approaches to public identity and transformation have focused on Lady Gaga's persona in particular and have percolated through both biographical studies and those concerned with popular music and popular culture (Gray 2014; Bennett 2014). What this particular vein of research has advanced is the way that fans construct and co-create the public identity - essentially the persona - of the popular music star.

\section{PeRsona AND THE IMPLICATION OF Music's PERCEIVED MEANING THROUGH PERFORMANCE: VOICE, GESTURE AND AUTHORITY AND AUTHENTICITY}

Although some of this biographical literature around popular music stars has integrated the notion of the strategic construction of persona, most work has not investigated the multiple versions of public selves that are generated by musical performance and performers. It has also generally overlooked some of the work in both musicology and classical musical criticism that are essential for deciphering the value and position of persona in and through music. Four major exceptions to this are two icons of popular music and performance studies, Simon Frith and Philip Auslander, and two influential thinkers that have shaped the use and positing of persona in musicology, Edward T. Cone and Allan Moore.

Simon Frith, in his study of the value of popular music, places the performance in a categorical array of musical meaning, authority and authenticity. On one level, he identifies the efforts of pop performers to be "personally expressive" in a manner not privileged in classical and operatic genres (Frith 1996, 186-187). From this vantage point, Frith establishes perhaps the most interesting division of how to understand persona (though he does not employ the 
idea of persona) through the voice and further integrates Barthes' notion of the "grain of the voice" (Barthes 1977) in his analysis. Barthes points to the voice as something closer to the body and beyond language in its expression of music's meaning and pleasure. For Frith there is a division and tension of power in how music communicates meaning, in its divide between words and music and that between composer/writer and performer, he thus identifies the "voice" of music and who communicates to be an interplay of it being "a musical instrument,.. $a$ body,... a person and... a character"(Frith 1996, p. 187, pp. 191-192).

The voice as instrument for Frith establishes the clearly musical nature of the voice's integration into performance and its interplay with other instruments. The voice does identify something, usually - but not always - different from other instruments. In popular music, it leads and in that leadership, it establishes the meaning and significance of the music for the audience. Further - as Frith identifies - in its inflexions, it structures a relation to gender that further defines the experiential and as Frith categorises the "body" and ultimately the gestural transformations of music that moves it forward into levels of signification. From classical music, the predominant persona of "soprano", "baritone" and "tenor" are for Frith somewhat fixed and generally gendered identities for performers and strategically deployed for performance (Frith 1996, p. 187) - they are more what we would call instrumental or technical in their formation. Frith's analysis of classical/operatic singing overlooks rather bluntly the nuances of personal expression in these categorizations of roles: individual classical performers do produce individualized personas that have become recognizable stars throughout its long history. Nonetheless, Frith correctly identifies that in popular music there is a more obvious flowing interplay and role-playing that can define the use of timbre and style that can lead to what Frith links to the musical voice as "personally expressive" (pp. 191-197). Through that notion of selfexpression in the voice, the extension of the music persona through voice can be taken to identify perhaps the character formation of the music itself or the person who fulfils these performance roles and how they articulate their individuality through performance. Somewhere into this mix are other persons as musical personas that Frith lists as composers or writers who play a shifted role in comparison to literature, but nonetheless are implied particularly with perceived meaning of the music text. And, Frith makes the claim that the audience actually shapes the significance of these quite different personas of authenticity, deception, transformation and meaning as they make sense of music in their own contexts within collective and industrial attempts to configure these collective pleasures of music listening.

Augmenting the analysis of Frith's work is Philip Auslander's valuable research on the production of music persona through performance. Indeed, Auslander is one of the first to fully appropriate the idea of persona into music via performance studies. His early work that deals with the relationship between Brechtian levels of strategic performance and narrative and Derrida's textually derived notion of "differance" and how meaning is produced through relations of identity (Auslander 1986, 53-60) identify how Auslander has conceptualized persona in music as constructing a chain of signification to and from music/composition to performer/performance.

Auslander's use of persona is built from and beyond what he describes as the "personage" (Auslander 2006, 102) that David Graver conceived (2003) as well as the concept of "personalism" (Auslander 2006) that Stan Godlivitch developed to understand the play of personality in musical performance (Godlovitch 1998). Both of these scholars that Auslander investigates emphasize that performance can shape and personalize any form of music; but Auslander layers into this an analysis of the multiple social functions of persona that Goffman developed in two of his key works (Goffman 1959; 1974) and calls his approach a move "toward a performer-centred theory of musical performance" (Auslander 2006, p. 103). Through 
employing a series of valuable Goffman concepts - including framing, lamination and impression management - and integrating the idea of "musicking" (Auslander 2006, cited from Small 1998) as a process rather than an object, Auslander develops a sophisticated re-reading of the various formations of musical personas and how prevalent their variations can be between genres and actual formal and informal styles of performance (Auslander 2006, pp. 105-117). He coins a related term for when a performer is well-aware of their particular posturing and deploys it for defined ends as a "meta-persona" (pp. 116-117). Auslander's direction is very much connected to the negotiated construction of meaning that defines music with the involvement of the performer and audience along with the other contextual frames constructing perhaps several types of negotiated personas that music and performance can generate. Persona helps articulate stability of performance with audience expectations matching in some way the performers' musical presentation. Bodily and facial gestures, posture, dress, and genre play into what Auslander defines in the plural as musical personae (Auslander 2006).

Edward T. Cone, whose critical work comes from both a composer and classic performance of music tradition, provides one of the most useful divisions of music and its personifications and like Auslander, uses persona with a certain centrality for understanding the complex origins of music. Cone presents three versions of identity construction in music (Cone 1974, pp. 20-40). He uses persona to convey the way music is a version of the composer who has created the music. Persona captures both its connection to the composer and its fiction-like reconstruction; but his analysis takes this further in its identification of what he calls "a protagonist", which is embodied by the instruments and the production of the music itself. He appropriates the idea that there is a "subconscious" movement of identity through these levels as the instruments reflect the constitution of a particular identity for the music itself. Cone's use of subconscious is to imply the way that a persona migrates across from the composer into the music and vocal performance in some way that is unseen but present. To express the play of identity further in musical composition, Cone also employs the almost literary term of character to identify primarily the role of singers and the way in which they convey a sense of the person in and through the composed music and words. For Cone, the composer's persona "is to be posited as an intelligence embracing and controlling all the elements of musical that comprise a work" (Cone 1974, p. 109, derived from Maus 2004, p. 23)

Although many musicologists have been influenced by Cone's work on the personacomposer relationship (see for example, Gelbart 2003; Maus, 2004) his deployment of persona is perhaps best adapted and interpreted by the musicologist Allan Moore (2017). Moore, via many examples from rock and popular music of the 1960s and 1970s, develops an even more sophisticated reading of the layers of music and the relation that instrumentation can actually set the persona-like tone for how a singer articulates and expresses the meaning of a song. Conceptually, Moore explains accompaniment and the relational structures it entails as an environment that produces what he thinks is best called a persona for the music. He furthers his integration of persona to say that this play within an environment and accompaniment can produce multiple personas and even further variance depending on the audience or listener's knowledge and cultural connection to the music itself (Moore 2017, 276). Downbeats, percussion, particular structure of notes can also work to separate the perceived persona that a singer is conveying to a point where it is sometimes clear that the listener by this accompanying environment and tonal sound, does not believe the persona that is embodied in the performance. Out of this, in a manner similar to Cone's notion of the composer persona, but also a challenge to it, music can generate meanings beyond the singer and into the realm of the intention of the composer and the sensibilities of the listener. He concludes his essay with the provocative statement: "Even without consideration of production manipulation, concentration on that very rich amalgam which constitutes the track's personic environment is absolutely 
crucial if we are to fully experience the expressive richness of popular song" (Moore 2017, p. 294).

\section{EMOTION AND PERSONA IN MUSIC}

Much of what we have developed in this analysis of performance and its production of a musical persona intersects with other forms and types of analyses. Drawing from our review of these four theorists' approach to persona, it is clear that the performative facial and tonal expressions of singers in popular, classical and operatic music are evidence of the construction of a form of dual persona. On one level, the singer is producing a persona with these signifiers of emotion and, on another level, the actual tone, pitch, tenor, and duration of the music produces something of a persona for the music itself with at least some intention of emotive evocation. Stephen Davies, whose position is that we do not need the idea of persona to understand emotion in music, critiques the approach developed by scholars such as Jenefer Robinson (1997) as "hypothetical emotionalism". "Hypothetical emotionalism invites the listener to regard the various emotions expressed within a single musical span as unified with respect to the emotional life and experiences of the imagined persona" (Davies 1997, p. 98). The idea of a unified emotional expression of a feeling - a persona - and that music can provide a clear narrative that an auditor/listener can read depends on a massive amount of other shared meanings and contexts. Nonetheless, there is no question that music pushes people to discern an emotional meaning related to a character-like persona as they interpret music and its affective formations into sentiments.

Research into understanding this emotive persona of music has progressed in some interesting and valuable directions specifically because music itself often moves through our world as an indirect form of communication, a form that plays in the world of feeling and affect as it is interpreted by audiences singularly and collectively. Tom Cochrane attempted to summarize this reading of the relation of music, emotion and persona first through explaining that our reading of music's emotion has implied a persona-like relationship to the music itself (Cochrane 2010, pp. 264-267). In other words, music's form of expression personifies because it is believed to be a communicative form to exhibit emotion - a human characteristic. He acknowledges that music's emotive persona is probably developed through context and social knowledge about the music that has been shared, and thus different personas emerge from how an individual listener knows or interprets the music contextually (p. 266). Nonetheless, Cochrane attempts to interpret the musical style and invocation of two pieces of music that try to express a quite complex human emotion - jealousy - from within the frame of the experience of the music itself. His conclusion from this work is that the formal production of the music - the instrumental interplay in effect - can produce a direction towards an emotion if it is building an identifiable "persona": "By situating an appropriate mix of basic emotional content within a suitable context of interacting personae, the music should be capable of being directly expressive (and not merely symbolic) of a complex social emotion" (Cochrane 2010, p. 272).

Making sense of music as form of emotional persona can perhaps be better comprehended through a closer study of musical origins. Gary Tomlinson's speculative research on how early hominids began developing music hundreds of thousands of years ago helps better identify the relation music has to formations of communication (Tomlinson 2015). Tomlinson's reliance on linguistic and archaeological reading of early instruments explains how hominids developed music from an original relation with others. Sounds were linked to gestures as a way to work together in what he and others call "co-presence": the musical rhythms and related sounds that may have emerged from cooperative hunting build to a sense of mutual understanding. Even though music may have developed from instruments of communication or 
sounds of repetitive forms of hitting for cooking and making things, it eventually moved to what he calls "offline": the moment where early hominids were able to imagine events and translate those events into "stories" reconstructed through sounds that captured the emotion of those original events. Music as formalistic embodiments of humans/activity/emotions then emerges from these elaborate signifying chains and could be characterized as "protolinguistic" in these early moments. Through music's embodiment of these states of human "being" and "feeling", music can be seen as a formation of abstract notions of the feelings of self: as essentially personas working through in a communitarian way with a tribe/gathering. This offline and fictional notion of persona captures much of the allure of music in its infinitesimal reconstruction of emotional connections and disconnections of humans with each other.

\section{PERsona IN AND THROUGH MusicAL TEChNIQUE AND TECHNOLOGY}

This long arc of tracing the origins of music provides some clear links to its reformation of individual activity into some collective experience that is through music enacted and made into a formation of the public self. Music produces a quite different persona constellation than the art form of literature as individuals reconstruct musical meaning into personalized, collectivized and environmental memories. To take this form of persona reconstruction in and through music further, it is useful to see music as a technique and related, sometimes quite closely, to technology. The musical instrument as some authors will avow expresses a personality through its sonic structuration.

Performance and composer as author are the most obvious connection to persona in music; however, the complexity of music, with its various elements involved its production and formation, points to other types of persona analysis. The bibliographic work of twentieth century song identification by Cooper et al. (2003) points to the way that we think of instruments as defining identity. Hundreds of songs are identified and linked to a state of being for the song through their use of an instrument in a title: from accordion, fiddle and guitar to the zither, the authors listed 250 popular songs from 1910 to the 1990s that gave prominence to the narrative and emotional meaning of a musical instrument in songs (Cooper et al. 2003, 38997). In other words, instruments serve as an intermediary of emotional persona when they are caricatured for strategic purposes through lyrics and musical style. As some of the research in this special issue identify, instruments then serve as a way to express some of the core meanings and narrative of an individual performer: their very public identity is crafted and shaped by their relationship and mediation through their own instruments (Fairchild 2019).

Technology also transforms music in other ways that can also be aligned to some aspects of persona. Dave Laing's (1991) study of the introduction of the phonograph perhaps points to the way that imagined performance became part of popular music at the end of the nineteenth century. Recorded music produced a sense of what we describe above as "copresence", but the co-presence is imagined by the listener and thus a reconstructed notion of the performer is built from available images, attempts to see a performer live, and renditions of music by other performers who have shared recorded music in public as a way to define their own public personas relation to the recorded versions of songs.

This complex relation of persona and technology becomes even more interesting when we integrate Frith's original analysis of the play of the microphone (Frith 1996, pp. 187-9) in transforming performance and how performance can be further configured through recording. The microphone allows the performer to play with meaning and expression; it provides a new "affordance" (see Norman 1988) for the performer to convey to a live audience (and a recorded one) very personal and intimate intonations of singing that would have been impossible in an 
era of concert performance that had to focus on acoustic projection to a large physically present audience without the technology of electric speaker enhancement.

Serge Lacasse's work on the technology of recorded music further augments this understanding of technology, performance and the production of persona-like meaning of popular music. Through his analysis of the sonic manipulations that Peter Gabriel integrates into two of his songs from different decades for emotional expression, Lacasse is able to articulate how a contemporary vocal performer with instrumental accompaniment can produce a musically identifiable and nuanced character/personage/persona specifically related to the particular song (Lacasse 2005).

Equally significant in the meaning of musical personas and technology is what Auslander describes as the process of "mediatization" of musical performance. The transformation of music performance into the televisual, Auslander explains is at least partly a process of remediation (Auslander 2008, p. 6; from Bolter and Grusin 1996), where performers and stagecraft from past technologies are integrated into the form of the current version. Variations of this persona remediation can be seen in early television and performers' efforts to construct the sensation of live performance on major American programs such as The Ed Sullivan Show in 1960s America along with the British Top of the Pops, which began in 1964. However, these mediatized structures are never completely stable: new musical personas emerged with the rise of video music in the 1980s. Narrative reconstructions permeated the meaning of the music as persona and, with even greater intensity, the public personas of musicians through filmic as well as advertising/promotional codes: music was transformed into a newly mediatized and remediated frame (Aufderheide 1986; Frith, Goodwin \& Grossberg 1993).

\section{RECENT PERsona STUdies RESEARCH AND ITS IMPLICATION FOR MUSIC AND PERSONA}

Through these various lenses, we have reviewed the way that music and persona intersect. It is readily apparent that music as a cultural form, practice, technology and performance has generated some distinct directions in how persona can be conceived. The collection of essays in this special issue will provide an even greater focus on other ways that music leads to a reconceptualization of persona as a research direction. It is also apparent that new directions in persona studies have not yet found their way into the study of music and musical culture. Before we provide an introduction to the works in this special issue, it is worth exploring whether persona studies can inform the future development of music and persona research. The range of material that has been generated in the last 10 years in this emerging field cannot be summarized adequately here; what we will attempt to identify are some key concepts in persona studies and provide the outline of how they may help understand musical persona further.

\section{Historical origins: Musical persona}

Music has a long history of what has been called "personafication" (Marshall, Cruz \& McDonald, 2018), where persons and personalities are imbricated into a continuing and strategic process of constructing persona. Persona and prosopon, its Greek predecessor, were techniques to "mask" the performers' identity. In the structure of Greek theatrical performance, the "chorus" represented a narrative mask in its mapping of activity, but also embodied singing (see, for example, Menander 1991). Music then is part of the communicative structure of persona that needs further exploration and integration into our current investigation of musical persona. 
Moreover, there is a mountain of historical literature that charts and maps music and identities that is too vast to summarize here. What is needed in the future is a re-engagement with that research from musicology and cultural history to see how it can be utilized to understand musical persona even further.

\section{Brand and musical persona}

Genre and music clearly inform our conceptualization of what a musical performance means. It provides context and socially built signifying structures that identify what might be called a persona range; but genre indexically points to the way that music is also a commodity form in its capacity to identify why an audience would be drawn to a performance or purchase, download or stream a recording. It further points to how the individual performer in this commodity structure is a brand and their formation of performance and identity through their music maintains and sustains the brand. As with many other domains of contemporary life, music fits into the corporate models of how difference and differentiation is represented. Music persona, when considered in branding terms, is a strategic reformation of music for economic exchange as cultural and emotional engagement are translated and retranslated into commercial value. One vital direction for research in musical persona then is to integrate the extensive work that has explored branding and music (see Lieb 2013; Carah 2013; Meier 2017)

\section{Social media transformation of musical persona}

A central impetus behind the emergence of persona studies was the online transformation of the public self. There are a myriad ways in which this would also transform our conceptualization of musical persona. Joy White's recent study of how music performers can connect to their audiences online points to a fundamentally different form of participation, engagement and, for the performer, public identity. White describes how a particular music genre, Grime, that was made an outlier in the British music scene for over a decade, has connected to groups transnationally to form clear fan bases for the performers, specifically via online culture (White 2015). Nancy Baym's extensive work investigating the online transformation of music makes the valuable analysis through the concept of "gig workers" that contemporary music describes a changed structure of intimacy and, for the performer, "relational labor" (Baym 2018, 16-21). Through her interviews with performers, Baym revealed the way musicians now have to construct an often self-driven entrepreneurial continuous connection with their followers in order to maintain their music persona identities. Baym also makes the important point that music as an industry was fundamentally shifted with the breakdown of record sales as early as the late 1990s. Augmenting this change, Baym further explains, was the emergence of MySpace - the social media precursor to Facebook, but also a form of connection that was from 2002 one of the new flows of connection for musical performers with their audiences in the twenty-first century (Baym 2018, pp. 10-11).

This research into music's changed status in regards to public identity, performance, and connection, has been peripherally connected to parallel research in persona studies. Along with this special issue, what could be further developed is an integration of the related terminology that research into persona could help in analysing music and its transformation in the era of social media. For instance, it is useful to identify further the registers of persona that have developed in recent work. Integrating the personal, the public, the intimate and the professional as registers that attempt to describe the constructed online music persona might be useful. Extending Nancy Baym's work on the private and the public and its intersection with the commercial, it may be valuable to play with the term "privlic", which has been developed in related work on contemporary publics (Marshall 2016) and in Marshall, Moore and Barbour's book on persona studies (2019, pp. 207-9). Although there may be a number of other useful 
terms that could assist in the nuancing and development of the study of musical persona and its online reconfiguration, linking Baym's work with the concept of intercommunication (Marshall et al. 2019, 47-53) - the blending of the interpersonal with the highly mediated as a structural form in online culture - might capture the particular way that music and its formation of performing personas moves in and through mediatized technology to communicate emotionally and relationally with its audience.

\section{Collective identity and its relation to musical persona}

The study of music has allowed for a particularly fruitful investigation of the formation of audiences: these have been characterized into persona-like identities through understanding the relationship produced with a concert crowd and how it structures a kind of co-presence and sharing among fans engaged with the music. One of the most significant conceptual developments in understanding persona - that it is a strategic formation of identity designed to move into collective worlds - more or less describes how music moves through our culture. Music produces collectives; musical personas can be thought of as strategic formations through musical performance to produce relations to this collective and shared culture. The formation of collectives is dependent on the related ways in which collectives connect. In contemporary culture, these connections are enhanced and transformed through online cultural exchanges and sharing. What emerges from both the strategic nature of music personas integrating into collectives and from the collective formations related to musical culture is understanding collectives as a type of persona perhaps not fully investigated in current research. Music thus presents a challenge to extend the analysis of what we might now call collective persona to capture the communicative and emotional connections of what has usually been described as audiences. However, the concept of audience perhaps no longer embodies the nuanced nature and activity of the current collective that has been connected to these persona networks.

\section{Where Else Might We TAKe "Persona”?}

As noted above, there are many areas of inquiry in the study of musical persona that have not been as thoroughly explored as they might have been. Remarkably, these unexplored areas elide some of the most powerful forces we experience in our everyday lives. The primary suite of such forces is, of course, capitalism. But the inclusion of capitalism in studies of musical persona when it has been defined as celebrity more often than not tends towards a kind of generic capitalism, simply called "the market," or more broadly identified as part of just one more "perspective" in ongoing debates over the nature of "the culture industry". Capitalism as market is most often included not as an analytical object, but as a foil, an opportunity to yet again explain why the culture industry perspective generally, and Adorno in particular, have got it perpetually wrong about fans, celebrity, and fandom, a trope that has persisted for an extraordinarily long time. Indeed, there are few better examples of the presumption of a generic "market" or model of capitalism than the continuing decades-long rebuttal of Adorno's various claims about popular music. (For a demonstrative list see Fairchild 2008, p. 7; see also Meisel 2010; Cinque 2016, p. 443; Duffett 2014, pp. 167-9). It is almost as if this perversely ahistorical disciplinary ritual is innocent of the transformations that capitalism and the market in music have experienced since Adorno last wrote about popular music. This is especially problematic given that contemporary capitalism, most often called "neoliberal capitalism," has historical capacities its antecedents did not. Of particular importance is the intersection of social media and the subjectivities produced under the conditions of neoliberalism, potentially linking us to emergence of persona as a defining operative concept in this area of research. 
While the comparatively recent concepts of neoliberalism and the "entrepreneurial self" have made mostly tentative appearances in the literature on musical celebrity, broader work on each points us to a potentially substantial reimagining of musical celebrity and persona (Chapman, 2018; Taylor, 2016; Flisfeder, 2015; Marwick, 2015). Both concepts offer an opportunity to trace particularly contemporary modes of public being across genres and traditions as well as the ability to work backwards historically through familiar cases with the benefit of these new lenses. We may find far more common ground in the ways in which, say, late nineteenth century opera stars or crooners in the 1930s or rock stars in the 1970s were socially constructed as famous musicians, than previously thought. Familiar historical narratives might be pried back open through an examination of the circumstances these figures have always shared. In other words, first we need to accept that capitalism, in its many varied historical formations, has long acted as a broadly encompassing, transcendent category shaping both human agency and its myriad material manifestations in the development of forms of selfhood and their expression in music. Then, we might be able to work to link musical traditions with few immediately apparent aesthetic commonalities, but many more readily apparent social and economic connections. Such work might serve to highlight the subtle couplings of tradition and selfhood, authority and voice that have defined music in public across musical traditions in the production of musical persona that might otherwise resist analysis. Thus the answers to our familiar questions (Who bestows authority? Who perceives authenticity? How are these produced?) might find intriguing parallels or divergences across musical traditions and historical epochs. As Straw has suggested, while subjectivity "will remain, as one of the congealed (or distributed) forces which travels with a work," it is not "the key and determining terrain on which the decisive processes in cultural life are played out." (Straw 2010, p. 215).

From this, we may be able to draw a more complex and finely tuned understanding of the long-cited "negotiated" encounters between audiences and artists. For instance, the concept of celebrity being a kind of "negotiation" between fans and artists is usually taken as a given in studies of musical celebrity and often implies a kind of common, if not level, playing field between the various parties involved. However, given that several defining aspects of contemporary capitalism have received only glancing attention in studies of popular music celebrity, there is much to be gained from closely examining the nature of these encounters between fans and perhaps a wider conceptual analysis of musical persona and its construction as a celebrity commodity. Specifically, the market is far too often talked about as if it is some kind of adversarial entity to fandom, when in fact, it is its animating force. More specifically, neoliberal capitalism is both provider to and co-conspirator with contemporary fan cultures, helping to constitute the public selves of artists and fans simultaneously, often through markedly similar communicative means. To put it bluntly, everyone wants more or less the same things from these encounters: extensive communicative and emotional connection through a continuing riot of sensory excitement. It is just that the different parties have different ways to facilitate and benefit from them.

The main difference is the power and consequences of the respective forms of communicative agency used by fans, musical celebrities, and those who facilitate their encounters and connections. The power and consequences of each do not simply rest on the expansiveness of the networks within which each participant operates, but also on the legitimating tools that structure and shape these networks. The most consequential of these tools rest within the music industry. They include the infrastructure to produce useful and unique knowledge about the market in music (i.e. data, demographics, etc.), the ability to translate these forms of knowing into useful forms of understanding across the full range of "stakeholders" (attracting investors, sponsorships, conducting public relations campaigns, etc.), 
the power to enforce the recognition of these factors within the market for music (defining and dominating the market), and then the capability to develop the strategies and calculations needed to make these tools operational in order to economically exploit specific conditions and circumstances. These are the fundamental forces that create, shape, and direct the musical personas that crowd the landscape of popular culture and we have yet to grapple with them substantively enough. Audiences, by contrast, do not have any of these capabilities, but instead can only participate by having their agency elicited, managed, and used to sustain existing markets and the social relationships they produce. Positing the social relationships between artists and audiences produced with these tools simply as a "negotiation" between artist and audience really does miss the point. Again, we might find that our oft-asked questions (What are the terms on which these negotiations take place? What are the sites of agency? How do we distribute or apportion agency and its consequences?) have new ground on which to work and actually reshape our reading of the persona in music as constituted by complex patterns and forms of communication strategies derived industrial-like relations.

Finally, we need to take into serious consideration the systemic processes that produce musical personas specifically by understanding them as systemic, that is reflective of a coherent logic and structure larger than any iteration that any one entity may produce. Musical celebrity and the larger category of "persona" both act as a kind of pivot point at which the extraordinary and often invisible labours of a sprawling entertainment industry meet the always developing and momentary "tastes" or "preferences" of the audience, the latter being an entity almost too diverse in its constitution and forms of agency to cohere as a recognisable "thing." Again we can ask familiar questions (Where do the attributes of a persona come from? Who put them there? Who decides what they mean?) but our answers might lead us somewhere new.

This demands that we take into account the many forms of cultural intermediation that substantiate musical persona, following paths through what Straw (2010) calls the "unauthored, collective processes of dispersion and condensation by which sense-making assumes its material forms". We will need an expansion of the kinds of sources from which we might draw our understandings of the existing discursive formations, material forms of mediation, and symbolic content of contemporary musical persona. These might include: websites, magazines, fanzines, social media feeds, trade publications, specialist blogs, museum displays, brand associations, product sponsorships, curated playlists, awards shows, and the many forms of popular narrative non-fiction written by journalists, historians, artists, industry executives, managers, and producers reflecting on the entities, events, and social relationships we call the "music industry."

All of this is directed towards a common goal: the production of musical subjects (Fairchild 2014). But the goal is not, and has never been, a generic musical subject. Instead, the ideal musical subject is a paradoxical and contradictory one. The ideal musical subject must be both compliant and active, predictable and generative. This is because neoliberal consumer capitalism can only sustain itself by exciting as many expressions of agency as possible. But the consequences of this incitement to action are by definition unpredictable and risky. So these expressions of agency must increasingly and necessarily be subjected managerial discipline as measurable as forms of economic productivity. As scholars such as Jodi Dean have argued, the communicative relationships that define neoliberal capitalism produce relationships that have few clear boundaries between production and consumption. Instead, a central demand of contemporary capitalism is to incorporate as many forms of agency into economically productive relationships as possible, if necessary, by manufacturing entirely new kinds of relationships (Dean 2009). The kinds of relationships that produce the lifeblood of the tech industry, user data, are a central and unavoidable example of this. 
These processes produce musical subjects by using a continually evolving range of tools for assessing and understanding what particular forms of music might "afford" consumers. That is, the music industry must continually trace the many ways that music acts as a kind of socially organizing medium that helps people structure, share and make sense of their social experiences, and then produce some kind of measurable economic consequence from them. When something as simple as a tweet, like or post produces exactly this kind of consequence, how we understand musical celebrity and persona within this complex strategic milieu seems to be one of the major steps we need to take to situate where these music identities serve as valuable intermediaries in this new flow of capital.

\section{THIS SPECIAL IsSUE: THE PAPERS}

We have attempted to cover a great many issues, concepts and approaches in this introductory essay on musical persona. While much of what we have identified above intersects with the work of those contributing to this special issue, there are still many other areas that too few researchers have addressed in substantial ways. We would like to conclude this opening essay with a description of what our contributors are developing and arguing in their presented research that pushes both our interest in music and persona further and also identify ways to challenge the structures we have presented above in new and valuable ways. Importantly, there are a series of characteristic lacunae in cultural studies, popular music studies, and celebrity studies in music that call for further exploration. These most especially cluster around the often taken-for-granted distinctions and oppositions between the presentation of performative selves in different genres and traditions, and especially in the presumed contrasts between classical music and popular music. Somehow, popular music, despite its communicative, experiential, and economic dominance is still posited as a kind of subaltern, aesthetic "other" to a European classical tradition that itself is often thought to be somehow more free of the "compromises" that define the popular. It seems well past time to explore the common wells from which many contemporary and historical iterations of musical personas have sprung. Similarly, the concept of a "negotiated" encounter between audiences and performers made tangible by identifiable personas is an area of work too often left to existing presumptions about the arenas in which these relationships are enacted. This has often resulted in a somewhat atrophied understanding of some of the most fundamental forces that shape these encounters. Finally, it would seem crucial to develop a better understanding of the material and experiential traces etched into the multitude of contemporary musical personas by the systemic processes of mediation that produced them.

Elliott starts off this special issue by examining that seemingly most straightforward of personas, the aging rock star. He examines Bruce Springsteen's lengthy chain of personas as they have been reiterated and reconstructed through to his most recent work. The author reflects on the musician's practice of engaging his audience through the carefully wrought fictions in his songs and his equally crafted fictional personas in his performance of them. Elliott examines the subtle "dialectical tension between shape-shifting and layering" in Springsteen's various personas. He focuses on what he has called the artist's "late voice" and how it affords the opportunity to reflect on and reconstruct a fully autobiographical persona. He proceeds on the assumption that audiences are both invested in and conscious of the artist's persona as an articulated historical entity. He explores various expressions of this entity through Springsteen's recent performances, such as Springsteen on Broadway from 2018 and his autobiographical writings, which contain rich and extensive examples of self-fashioning.

From here, we move towards two very different examples of how artist personas are constructed. Deflem and Bomfim both focus on the processes through which very particular 
personas have been constructed, those of Lady Gaga and the twentieth century spiritualist Rosemary Brown, respectively. These articles examine how each figure reflected and challenged prevailing cultural and gender dynamics in their respective spheres of influence. Each article, while dealing with subjects separated by time and the form of their fame, nevertheless point to underlying continuities in the historical trajectory of musical celebrity that can be something of a surprise. Deflem pursues the processes through which Stefani Joanne Angelina Germanotta worked to construct her performative persona, which she calls Lady Gaga. Deflem presents a sociological account of the process of Germanotta renaming herself, relying on Goffman's ideas about naming and identity in the management of one's public life. Taking a somewhat marginal observation on fame from Goffman's 1963 book Stigma, along with more familiar ideas from Goffman's 1956 work The Presentation of Self in Everyday Life, Deflem asserts that Gaga's naming of herself is particularly relevant to understanding the various forms of privileged social status she has accrued from this act and the subsequent social relationships produced by it and the socially produced meanings upon which they were founded. He notes that this phenomenon of renaming has not only persisted, but flourished in recent years.

Bomfim examines the case of Rosemary Brown, a twentieth-century performer and spiritualist who claimed that her connections with the spirits of dead composers allowed her to more or less transcribe the heretofore unknown works of composers such as Bach, Mozart, Chopin, Liszt and others. Describing herself in the most mundane terms, Bomfim reports that Brown did so as part of a larger effort to shape her public persona in such a way as to lend her claims towards her specific brand of spiritualism more legitimacy. Further, her repeated claims to a personal modesty and humility had a distinctly gendered quality, as Brown insisted she was merely a humble housewife and vessel through which the accomplishments of great men might be facilitated. Despite the obvious and extensive differences between Brown and Lady Gaga, we can see several continuities in the ways each constructed their selves in public.

The two articles that close out this issue, those by Johinke and Fairchild, both focus on cultural intermediation. Each traces distinct forms of influence through multi-sensory, multimedia forms of communication about music. Each suggests or explores a broader historical sensibility found through these forms of communication and examines the distinct forms of power they exert. Fairchild focuses on the role of museum displays as an extension and confirmation of the consensus histories of popular music and its most celebrated musicians. The use of objects, in this case guitars, is posited as a way to make the symbolism of artistic "greatness" tangible and material without subverting or dissipating its symbolic affect. Further, Fairchild argues that merely "reading" these displays for their symbolism is insufficient in understanding their meaning and impact. Instead, it is the immediate and demonstrable materials qualities these instrument possess, and specifically not their forever-stilled soundproducing qualities, that lend a literal weight to the narratives popular music museums produce about their subjects.

Johinke takes two editors of the high-profile music magazine Rolling Stone as her subject, examining persona through the reflections of two women who edited the Australian iteration of the magazine. She examines the role of the popular music magazine editor, not simply as mediator, but as self-fashioned personas in their own right. She examines how the editor imposes order on materials to such an extent that their work can be considered a significant influence on cultural norms and values. Further, editors do so while also striving to sustain a publication through the management of complex webs of interdependent entities such as sponsors, advertisers, readers, and owners, while also trying to maintain ethical relationships with their publics. The complexities and difficulties faced specifically by women working in a traditionally male-dominated position offer some perspective on how music media have 
changed in recent years. Johinke's broad case studies offer rich insights into this form of work and suggest a vibrant social history of the values and ideals pursued and embraced by media workers and their publics.

\section{END NOTES}

i As much as we have worked to include the various strands of music, partly because of our own expertise, we do acknowledge that this issue and our introduction have perhaps privileged popular music over classical and operatic music. We do hope that this mapping of music and persona will lead to scholars closer to other traditions in musicology, ethnomusicology and music history to extend this important work further.

\section{WORKS CITED}

Aufderheide, P 1986, 'Music videos: The look of the sound', Journal of Communication, vol. 36, no. 1, pp. 57-78.

Auslander, P 2008, Liveness: Performance in a Mediatized World. 2nd edition. Routledge, New York.

- 2006, 'Musical personae,' TDR: The Journal of Performance Studies, vol. 50, no. 1, pp. 100-19.

- 1986, 'Logocentrism and difference in performance theory', Performance Theory Art and Criticism vol. 1, p. 60.

Barthes, R 1973, Mythologies, Paladin, St. Albans.

- 1977, 'The grain of the voice' in R Barthes (translated by Stephen Heath) Image, music, text, Hill and Wang, New York. pp. 179-189.

Baym, NK 2018, Playing to the crowd: Musicians, audiences, and the intimate work of connection, NYU Press.

Bennett, L 2014, 'If we stick together we can do anything': Lady Gaga fandom, philanthropy and activism through social media', Celebrity Studies vol. 5, no. 1-2, pp. 138-152.

Bolter, JD \& Grusin, R 1999, Remediation: Understanding new media, MIT Press, Cambridge, MA.

Chapman, Dale 2018, The Jazz Bubble: Neoclassical Jazz in Neoliberal Culture. University of California Press, Berkeley, CA.

Cinque, T \& Redmond, S 2017, 'Intersecting David Bowie', Continuum vol. 31, no. 4, pp. 495-498. doi: 10.1080/10304312.2017.1334382

- 2016, 'Digital shimmer: Popular music and the intimate nexus between fan and star', in P. David Marshall and Sean Redmond (eds) A Companion to Celebrity, Wiley, Malden, Ma, pp. 440-55.

Cochrane, TOM 2010, 'Using the persona to express complex emotions in music', Music Analysis vol. 29, no. 1-3, pp. 264-275. doi: 10.1111/j.1468-2249.2011.00321.x.

Cone, ET 1974, 'Persona, protagonist and characters', in ET Cone (ed), The composer's voice (No. 3), University of California Press, Berkeley, pp. 20-40,

Davies, S 1997, 'Contra the hypothetical persona in music', In M Hjort and S Laver (eds), Emotion and the Arts, Oxford University Press, New York, pp. 95-109.

Dean, J 2009, Democracy and Other Neoliberal Fantasies Communicative Capitalism and Left Politics, Duke University Press, Durham.

Duffett, M 2014, 'Celebrity: The return of the repressed in fan studies?' In L Duits, et al. (eds) The Ashgate Research Companion to Fan Cultures, Ashgate, Farnham, pp. 163-80.

Dyer, R 1998, Stars, BFI Publishing, London.

Fairchild, C 2008, Pop idols and pirates: mechanisms of consumption and the global circulation of popular music, Ashgate, Aldershot.

— 2014, 'Popular music.' In J Maguire and J Matthews, The Cultural Intermediaries Reader, Sage, London, 125-33. 
Flisfeder, M 2015, 'The entrepreneurial subject and the objectivization of the self in social media' South Atlantic Quarterly vol. 114, no. 3, pp. 553-70.

Frith, S 1996, Performing rites: On the value of popular music. Harvard University Press, Cambridge, Ma.

Frith, S, Goodwin, A \& Grossberg, L (eds) 1993, Sound and vision: the music video reader, Routledge, New York.

Graver, D 2003 [1997], 'The Actor's Bodies.' In P Auslander (ed), Critical Concepts: Performance, pp. 157-74. Routledge, London.

Godlovitch, S 1998, Musical performance: a philosophical study. Routledge, London and New York.

Goffman, E 1959, The presentation of self in everyday life, Doubleday Anchor Books, Garden City.

- E 1974, Frame analysis : an essay on the organization of experience, Harper Colophon Books, New York.

Gray II, RJ (ed.) 2014, The performance identities of Lady Gaga: critical essays, McFarland, Jefferson.

Guilbert, G-C 2002, Madonna as postmodern myth: How one star's self-construction rewrites sex, gender, Hollywood and the American dream, McFarland, Jefferson.

Lacasse, S 2005, 'Persona, emotions and technology: the phonographic staging of the popular music voice', CHARM Symposium, Vol. 2, pp. 1-12.

Laing, D 1991, 'A voice without a face: Popular music and the phonograph in the 1890s', Popular Music, vol. 10, no. 1, pp. 1-9.

Gelbart, M 2003, 'Persona and voice in the Kinks' songs of the late 1960s', Journal of the Royal Musical Association, vol. 128, no. 2, pp. 200-241.

Marshall, PD, Moore, C \& Barbour, K 2019, Persona Studies: An Introduction, Wiley Blackwell, Hoboken, NJ.

- 2016, 'When the private becomes public: commodity activism, endorsement and making meaning in a privatized world', in PD Marshall, G D'Cruz, S McDonald \& K Lee (eds), Contemporary Publics: Shifting Boundaries in New Media, Technology and Culture, Palgrave Macmillan, New York, pp. 229-45.

- 2014, Celebrity and power: Fame in contemporary culture, 2nd Edition, University of Minnesota Press, Minneapolis.

- 2017, 'Productive consumption: agency, appropriation and value in the creative consuming of David Bowie', Continuum vol. 31, no. 4, pp. 564-573. doi: 10.1080/10304312.2017.1334379

Marwick, A 2016, 'Instafame: Luxury selfies in the attention economy', Public Culture, vol. 27, no. 1, pp. 137-60.

Maus, FE 2004, 'The disciplined subject of musical analysis', In A Dell'Antonio (ed.), Beyond structural listening? Postmodern modes of hearing, University of California Press, Berkley, pp. 13-43.

Meier, LM 2017, Popular music as promotion: Music and branding in the digital age, John Wiley \& Sons, Hoboken.

Meisel, P 2010, The Myth of Popular Culture: From Dante to Dylan. Wiley-Blackwell, Malden.

Moore, AF 2017, 'The Persona-Environment relation in recorded song', In M Spicer (ed.), Rock Music, Routledge, London, pp. 275-294.

Morin, E 1972, 'Les stars', Paris, Éditions du Seuil.

Norman, DA 1988, The psychology of everyday things. Vol. 5: Basic Books, New York.

Small, C 1998, Musicking: The meanings of performing and listening. Wesleyan University Press, Middletown.

Robinson, J 1994, 'The expression and arousal of emotion in music', The Journal of Aesthetics and Art Criticism vol. 52, no. 1, pp. 13-22.

Straw, W 2010, 'Cultural production and the generative matrix: A response to Georgina Born.' Cultural Sociology, vol. 4, no. 2, pp. 209-16.

Taylor, T 2016, Music and Capitalism: A History to the Present. University of Chicago Press, Chicago. 
Tomlinson, G 2015, A million years of music: the emergence of human modernity, MIT Press, Cambridge.

White, J 2015, “Just type my name in Google and see what comes up": Creating an online persona in the urban music industry' https://ssrn.com/abstract=2569347 or http://dx.doi.org/10.2139/ssrn.2569347

Wiles, D 1991, The Masks of Menander: Sign and Meaning in Greek and Roman Performance. Cambridge University Press, Cambridge. 